\title{
Significados Atribuídos por Mães Acerca do Acolhimento Institucional, Reintegração e Rede de Atendimento
}

Meanings Attributed by Mothers to Residential Care, Reintegration and Assistance Network

Significados Atribuídos por las Madres Acerca de la Acogida Institucional, Reintegración y Red De Atención

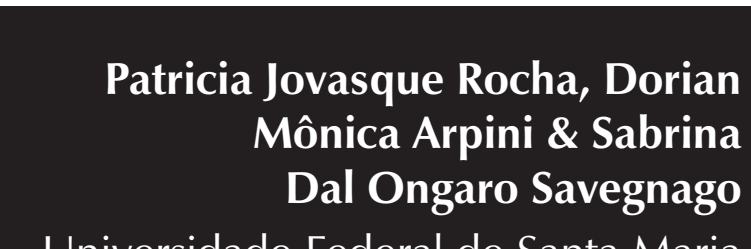

Universidade Federal de Santa Maria

http://dx.doi.org/10.1590/1982-3703002312013 
Resumo: Esta pesquisa objetivou conhecer, através de entrevistas, a experiência de mães de crianças e adolescentes reintegrados acerca do trabalho realizado pela rede de atendimento durante a aplicação da medida de proteção e a reintegração. Os dados foram analisados através da Análise de Conteúdo. Os resultados indicam que tanto as mães quanto as crianças e adolescentes receberam atendimento das equipes técnicas (psicólogas e assistentes sociais) da instituição de acolhimento bem como de outros profissionais da rede durante a aplicação da medida e após a reinserção. Foi possível perceber que as famílias fizeram uma avaliação positiva dos atendimentos recebidos, reconhecendo a importância dos mesmos para o processo de reintegração familiar. Os resultados indicam ainda que os participantes reconhecem mudanças na realidade do acolhimento institucional a partir da lei n. 12.010, em especial a proximidade família/instituição. As considerações finais sugerem a realização de novos estudos que contemplem as especificidades da realidade brasileira, sem, contudo, perder de vista os parâmetros nacionais.

Palavras-chave: Relações familiares. Crianças abrigadas. Saúde pública. Reintegração familiar.

Abstract: Based on interviews with mothers of reintegrated children and adolescents, this research aimed to learn about their experience with the work carried out by the assistance network during the process of protection measures and reintegration. Data were analyzed using Content Analysis. Results indicate that mothers, children and adolescents received assistance from the technical teams (psychologists and social workers) of residential care institutions and the professionals of networks throughout the period of protection measures, and after reinsertion. The families evaluated positively the assistance received, recognizing its importance to the process of family reintegration. Results evidence that participants recognize changes regarding the residential care after Law 12.010, especially related to the family/institution closeness. Final considerations suggest the need for further studies to address specificities of the Brazilian reality without losing sight of the national parameters.

Keywords: Family relations. Sheltered children. Public health. Family reintegration.

Resumen: Esta investigación tuvo como objetivo conocer, a través de entrevistas, la experiencia de las madres de niños y adolescentes reintegrados sobre el trabajo realizado por la red de atención durante la aplicación de la medida de protección y la reintegración. Los datos fueron analizados mediante el Análisis de Contenido. Los resultados indicaron que tanto las madres como los niños y adolescentes recibieron atendimiento de los equipos técnicos (psicólogos y asistentes sociales) de la institución de acogida, así como de otros profesionales de la red durante la ejecución de la medida y después de la reinserción. Fue posible percibir que las familias hicieron una evaluación positiva de la atención recibida, reconociendo la importancia de la misma para el proceso de reintegración familiar. Los resultados también indican que los participantes reconocen los cambios en la realidad de la acogida institucional a partir de la ley 12.010, en especial la proximidad familia/ institución. Las consideraciones finales sugieren la realización de más estudios que aborden los aspectos específicos de la realidad brasileña, pero, sin perder de vista los parámetros nacionales.

Palabras-clave: Relaciones familiares. Niños acogidos. Salud pública. Reintegración familiar.

\section{Introdução}

Acolhimento institucional e reintegração familiar a partir da lei n. 12.010

O Estatuto da Criança e do Adolescente (Brasil, 1990) prevê o acolhimento institucional como uma medida de proteção de caráter provisório e excepcional (Art. 101, § $1^{\circ}$ ), utilizada para crianças e adolescentes que tenham seus direitos ameaçados ou violados. Essa medida é aplicada quando nenhuma das opções anteriores a ela é suficiente para colocar a criança e o adolescente em situação de proteção. Além disso, deve priorizar o fortalecimento dos laços familiares e comunitários, visando à reinserção da criança ou do adolescente em sua família natural ou extensa, ou, caso a reinserção não seja possível, a colocação em família substituta (Brasil, 1990; Silva \& Arpini, 
2013). Dessa forma, incentivos são necessários para que todas as possibilidades de a criança/ adolescente permanecer na família sejam esgotadas, pois por mais rápido que possa ser tirar uma criança de sua família, seu retorno não o é (Silva, 2012; Silva \& Arpini, 2013).

Por ser uma medida excepcional, os motivos para a colocação de uma criança ou adolescente em instituição de acolhimento devem ser amplamente discutidos. A retirada do ambiente familiar deve ser realizada apenas quando isso se mostrar imprescindível para o bem-estar dos meninos e meninas. Entretanto, o Brasil é um país com tradição na institucionalização de crianças e adolescentes em situação de vulnerabilidade, a qual é historicamente tecida na desqualificação da população a que estes pertencem (Moreira \& Miranda, 2014; Silva, Mello, \& Aquino, 2004). Dessa forma, frequentemente meninos e meninas são encaminhados a instituições de acolhimento devido à reduzida capacidade dos pais de proverem os meios para o sustento e a educação de seus filhos. Isso significa que muitas crianças e adolescentes brasileiros são privados da convivência familiar e comunitária, fundamentalmente em razão de suas condições socioeconômicas (Cavalcante, Silva, \& Magalhães, 2010; Moreira \& Miranda, 2014; Rizzini, Rizzini, Naiff, \& Baptista, 2006). Assim, é necessário que se criem formas de suporte básico à família, que sejam acionadas antes que os problemas se tornem tão graves a ponto de o acolhimento ser inevitável. Nesse sentido, o contexto da família deve ser considerado tanto parte do problema, quando esse existir, quanto fonte de recursos para o melhor encaminhamento da situação (Moreira \& Miranda, 2014; Rizzini et al., 2006; Souza \& Carvalho, 2014).

Sabe-se que a pobreza, como citada, não deve ser motivo de acolhimento institucional. Se os vínculos são satisfatórios, a criança e o adolescente deveriam ser mantidos em seu contexto familiar, garantindo-se à família a inclusão em programas de apoio do governo (Lopes \& Arpini, 2009). Assim, é necessário que se pense a respeito da ausência ou insuficiência de políticas públicas de emprego, moradia, saúde e educação, as quais poderiam dar suporte às famílias nos momentos de dificuldade. Diante dessa ausência de políticas de proteção social, que deveriam ser implementadas pela esfera pública com a participação da comunidade, os profissionais e mesmo as famílias se deparam com a pressão para que sejam encontradas soluções para as complexas situações vividas por seus membros (Rossetti-Ferreira et al., 2012). Dessa forma, investir em mecanismos de inclusão social das famílias em programas de apoio ao desenvolvimento poderia evitar os processos de acolhimento institucional e reintegração familiar prolongados, ampliando suas redes de contato e relações sociais, favorecendo que o contexto familiar ofereça melhores condições para o desenvolvimento de seus filhos (Cavalcante et al., 2010; Serrano, Almeida, \& Rossetti-Ferreira, 2013). É necessário, portanto, o desenvolvimento de trabalhos direcionados para os vínculos familiares e para o apoio às famílias, bem como de políticas de atenção às mesmas (Moreira \& Miranda, 2014; Silva \& Arpini, 2013; Vitale, 2006). Nessa direção, a família deve ser incentivada a retomar a relação com seus filhos durante a medida de acolhimento, como uma das estratégias de reconstruir a convivência familiar e integrar novamente o que precisou ser separado (Oliveira, 2007; Silva \& Arpini, 2013). Nesse sentido, destacase a importância da aproximação família/ instituição, a qual pode ser feita através de visitas, entrevistas ou grupos, nos quais se possa falar sobre os motivos do acolhimento, tirando desse o caráter punitivo que muitas vezes o definiu.

Desde o advento do Estatuto da Criança e do Adolescente (ECA), os acolhimentos institucionais vêm se modificando no sentido de oferecer atendimento personalizado e individualizado às crianças e adolescentes ali presentes, em grupos reduzidos de caráter residencial e na preocupação com a convivência familiar e comunitária dos jovens (Siqueira \& Dell'Aglio, 2012; Souza \& Carvalho, 2014). Essas modificações são de extrema importância, pois uma nova modalidade de atendimento demanda justamente a superação dessas propostas de atendimento marcadas pela coletivização e homogeneização do cotidiano (Guará, 2006).

Quando é necessário o afastamento do ambiente familiar e, assim, crianças e adolescentes passam a viver em uma instituição de acolhimento, 
os esforços devem ser voltados para que a reintegração se dê no menor tempo possível e para que as referências familiares sejam mantidas (Silva et al., 2004). Esse cuidado é importante, pois o próprio ingresso na instituição de acolhimento é um momento de tensão e rompimento de laços de parentesco e de afetos (Guará, 2006; Silva, 2012; Silva \& Arpini, 2013). Para a criança ou o adolescente institucionalizado, os efeitos gerados pela fragilidade dos vínculos familiares, já existentes, podem ser intensificados pela permanência por longo período em ambiente institucional (Cavalcante et al., 2010; Silva, 2012; Silva \& Arpini, 2013).

A fim de aprimorar os serviços de acolhimento institucional e reinserção familiar, foi aprovada, no ano de 2009, a lei n. 12.010 (Brasil, 2009). Ela dispõe sobre o remodelamento de leis vigentes em relação não especificamente à adoção, mas, em especial, ao acolhimento institucional e à reintegração familiar. Busca aperfeiçoar o sistema já existente de direito à convivência familiar e comunitária de todas as crianças e adolescentes, conforme já previsto no Estatuto da Criança e do Adolescente (Brasil, 1990). A lei n. 12.010 traz como principais modificações: a obrigatoriedade de reavaliação da situação da criança ou adolescente em instituição de acolhimento a cada seis meses, a preferência pela reintegração em sua família natural a qualquer outra ação e a permanência máxima de dois anos em acolhimento institucional (Brasil, 2009). Dessa forma, se a família biológica, incluindo a família extensa, puder ser apoiada para dar à criança o cuidado e o amor necessário, ela será a primeira a ser procurada, com vistas à reintegração familiar (Vitale, 2006).

Outra modificação trazida pela lei em questão diz respeito ao Plano Individual de Atendimento (PIA), o qual deve ser elaborado pela equipe responsável assim que a criança ou o adolescente chegar à instituição de acolhimento (Brasil, 2009). O PIA pressupõe que será traçado um caminho para atender as demandas de cada criança/adolescente, devendo conter: avaliação interdisciplinar do acolhido, compromissos assumidos pelos responsáveis e atividades a serem desenvolvidas (Art. 101, § 6으). Dessa forma, a rede de atendimento (composta por CRAS, CREAS, NASF, Juizado da Infância e Juventude, Conselhos Tutelares) disponível no município deverá ser acionada com vistas à reintegração da criança/adolescente à sua família de origem ou, caso essa reintegração não seja possível, à colocação em família substituta (Brasil, 2009). O plano individual de atendimento configura-se em um instrumento de fundamental importância no contexto do acolhimento institucional de crianças e adolescentes, pois garante que se tenha um olhar voltado a cada menino e menina acolhido individualmente, levando em consideração as especificidades de cada caso.

Dessa forma, há vários fatores que influenciam na permanência ou não de uma criança ou adolescente no seio familiar, como a inexistência ou ineficácia de políticas públicas e a falta de suporte à família (Rizzini et al., 2006). É necessário que se invista em políticas públicas e práticas sociais efetivas que sejam constantes e articuladas em rede. Porém, as medidas adotadas são, muitas vezes, insuficientes e desarticuladas, dificilmente atuando em nível preventivo (Rossetti-Ferreira et al., 2012). A formação e a articulação de uma rede de atendimento, na qual exista uma comunicação entre os serviços envolvidos, são fundamentais para o bom atendimento dessas crianças, adolescentes e suas famílias, principalmente por se encontrarem em situação de vulnerabilidade.

Equipe técnica do acolhimento e rede de atendimento

A equipe técnica do acolhimento institucional, composta por psicólogos e assistentes sociais, assume fundamental importância no processo de acolhimento institucional e reintegração de crianças e adolescentes, principalmente a partir da Lei n. 12.010 (Brasil, 2009). O direito à convivência familiar e comunitária, seguindo os preceitos do ECA e dessa lei (Brasil, 1990, 2009), está diretamente relacionado ao processo de desligamento institucional e de reinserção familiar, e a responsabilidade pela promoção, avaliação e preparação para essa reintegração fica a cargo da equipe técnica das instituições de acolhimento e da rede de atendimento (Serrano et al., 2013; Siqueira, 2012).

Dessa forma, um profissional presente e capacitado, que reflita sobre os aspectos jurídicos, psicológicos e sociais envolvidos no 
acolhimento, pode ser a garantia de que esses meninos e meninas não serão abandonados novamente. Além disso, o dia a dia de uma instituição de acolhimento pode e deve ser o espaço de novas rotinas que permitam a construção de um ambiente de crescimento pessoal, de reelaboração de projetos de vida, de cuidado mútuo e de aceitação das diferenças (Guará, 2006; Souza \& Carvalho, 2014). A equipe de atendimento da instituição deve estar preparada para ser a facilitadora dessa construção junto às crianças e adolescentes que ali se encontram.

A realização de um bom trabalho de recuperação das redes sociais de proteção pessoal e social por parte da equipe da instituição de acolhimento pode tornar possível o retorno da criança/adolescente à família, contribuindo para construir ou refazer vínculos afetivos e comunitários (Albuquerque, 2012; Silva \& Arpini, 2013; Vitale, 2006). A reintegração familiar se caracteriza pelo trabalho incansável de procura pelos familiares, identificando aqueles que estariam dispostos a assumir os cuidados com a criança ou o adolescente. Deve-se buscar o resgate da história da criança e de seus vínculos. Nesse sentido, o profissional deve fazer um mapeamento da rede familiar nuclear e extensa e de relações com a comunidade. Faz-se necessário o estabelecimento de uma relação de proximidade com as famílias, identificando os problemas e as ações necessárias para superar as fragilidades e obstáculos ao retorno familiar. Também se pressupõe que o profissional avalie as condições da família, atentando para a pluralidade que contempla a família no contexto atual.

Porém, não basta a realização de um trabalho que resulte na reintegração desses meninos e meninas. Após o retorno deles à convivência familiar, torna-se fundamental reavaliar as suas situações, levando-se em conta a influência de alguns fatores, tais como a avaliação negativa da participação da família nos atendimentos psicossociais e o fraco desempenho da rede de serviços acionada (Cavalcante et al., 2010). O acompanhamento dessas famílias pode evitar uma reinserção mal-sucedida, com uma nova quebra de vínculos, a qual pode trazer ainda mais sofrimento tanto para os pais quanto para os filhos.
A fim de que tanto as equipes técnicas das instituições de acolhimento quanto o Conselho Tutelar possam realizar seu trabalho, torna-se importante a existência de uma rede de atendimento que esteja de acordo com as necessidades das famílias, e que aja de forma articulada (Serrano et al., 2013; Siqueira, 2012; Souza \& Carvalho, 2014). As redes constituem formações dinâmicas e flexíveis, com contínua renovação dos participantes, abrangendo espaços geográficos, políticos e sociais (Rizzini et al., 2006). A construção dessa rede de atenção, a qual inclui serviços em diferentes níveis de complexidade, sugere mudanças na atuação das instituições de acolhimento, pois passam a ser um de seus elementos (Arpini \& Quintana, 2009), devendo agir de forma integrada com outros serviços, conforme indicados para cada caso. Essa rede deve dispor dos atendimentos necessários às crianças, adolescentes e famílias a que acolhe, estando preparada para atender à sua demanda (Albuquerque, 2012; Siqueira, 2012).

O trabalho em rede tem por objetivo a valorização do contexto de vida do indivíduo, priorizando o atendimento pelas instituições e pessoas que fazem parte do seu meio social (Rizzini et al., 2006). Dessa forma, a ideia de territorialidade assume fundamental importância, pois viabiliza esse atendimento do sujeito dentro de seu contexto social. Para que se constitua uma rede integrada, que ofereça atendimento integral às crianças, adolescentes e suas famílias, é essencial que ela esteja articulada com os diversos setores das políticas sociais, como assistência social, saúde e educação. Além disso, ela deve estar conectada aos Centros de Referência em Assistência Social/CRAS - proteção social básica - e aos Centros de Referência Especializados em Assistência Social/CREAS - proteção social especial (Rizzini et al., 2006). Voltando o olhar às redes de atendimento às crianças e adolescentes em vulnerabilidade social, é essencial que a intervenção profissional seja multidisciplinar (social, psicológica, jurídica), devido à multiplicidade de questões envolvidas e que afetam a convivência familiar (Albuquerque, 2012; Cavalcante et al., 2010).

O aprendizado para o trabalho integrado e sem competições é fundamental para o bom funcionamento das redes. Conhecer o 
modo como a rede funciona e os agentes nela envolvidos é essencial para que o trabalho seja benfeito e otimizado. Dessa forma, torna-se importante o investimento em capacitações aos profissionais para atuarem em rede, garantindo a promoção de ações articuladas (Rizzini et al., 2006). Também com relação ao acolhimento institucional de crianças e adolescentes, as equipes devem estar preparadas para identificar as melhores alternativas frente a essas situações, sendo fundamental a formação e a capacitação dos agentes sociais envolvidos (Siqueira, 2012). Pesquisas realizadas por Rossetti-Ferreira et al. (2012) apontaram a capacitação dos atores envolvidos nas medidas de proteção e a articulação destes num efetivo trabalho em rede, como imprescindíveis para o desenvolvimento integral das crianças e adolescentes em situação de acolhimento institucional.

As ações articuladas, como são propostas pela rede, são possíveis e trazem resultados que vão além dos que seriam alcançados caso fossem realizados de forma fragmentada e/ou isolada (Rizzini et al., 2006). Pensando nas redes de atendimento às crianças e adolescentes em situação de risco e vulnerabilidade social, apenas através de uma atuação "competente, capacitada, suficiente e articulada" é que será possível encaminhar de forma efetiva os casos e "fazer valer o direito à convivência familiar e comunitária" (Siqueira, 2012, p. 443). Nessa direção, este estudo objetivou conhecer o ponto de vista de mães de crianças e adolescentes acerca do acolhimento, da reintegração e da rede de atendimento.

\section{Método}

\section{Desenho do estudo}

Para atender os objetivos da pesquisa, optou-se por um método qualitativo, por entender-se que esse tipo de método se mostra o mais adequado. Isso porque permite conhecer em profundidade a "natureza de um fenômeno social" e os diferentes pontos de vista sobre esse fenômeno (Gaskell, 2005; Richardson, 1999, p. 79).

Foram realizadas entrevistas semi dirigidas, com roteiro previamente estabelecido, por entender-se que esse tipo de entrevista favorece o conhecimento interpessoal devido ao encontro face a face do entrevistado e do entrevistador facilitar a compreensão de uma série de fenômenos da pessoa do entrevistado (Turato, 2003). Richardson (1999) aponta ainda que esse tipo de entrevista favorece que o entrevistado possa discorrer de forma mais livre sobre o assunto proposto. As entrevistas realizadas foram gravadas e transcritas na íntegra. A análise dessas transcrições foi feita utilizando-se a Análise de Conteúdo proposta por Bardin (1977).

\section{Participantes}

Inicialmente, o estudo previa a participação da família, considerando a totalidade dos membros que a compunham. No entanto, ao entrar em contato com a realidade dessas famílias, identificou-se que em duas delas a mãe era a única figura adulta responsável pela casa, e nos outros dois casos os pais, em função do trabalho, não estariam disponíveis para integrar a pesquisa. Assim, participaram quatro mães e três adolescentes. Essas famílias foram incluídas no estudo a partir da indicação das equipes técnicas das instituições, considerando os critérios de inclusão previstos no estudo (ter passado pelo acolhimento institucional, ter sido realizada a reintegração familiar no ano de 2012 e esta ter no mínimo um período de quatro meses). Assim, considerando as especificidades do contexto onde a pesquisa foi realizada, ficou privilegiado o olhar materno.

Descrição dos participantes

Família A: Está vinculada à instituição de acolhimento 2. Ambos os pais têm 38 anos, sendo a mãe (A.) dona de casa e o pai agricultor. Com eles residem seis dos nove filhos, os quais têm15, 13, 11, 9 e 4 anos, além de um bebê de um mês. Destes, apenas o filho mais velho passou pelo acolhimento institucional, permanecendo institucionalizado durante sete anos (essa informação foi fornecida pela mãe. Segundo equipe técnica, o período de institucionalização foi de 13 anos). O motivo do acolhimento foi um conflito familiar envolvendo a mãe e a avó paterna do menino. O adolescente foi reintegrado no ano de 2012.

Família B: Está vinculada à instituição de acolhimento 1. A mãe (B.) tem 41 anos de idade, enquanto o padrasto tem 36 . A ocupação 
da mãe consiste em vender lanches em um trailer e a do padrasto em operar um carro de frete e som. B. possui cinco filhos, sendo que apenas dois residem com ela e o companheiro: duas adolescentes de 12 e 14 anos, além de seu enteado. Ambas as adolescentes passaram pelo acolhimento institucional, sendo que a mais nova esteve institucionalizada em dois momentos diferentes. O primeiro acolhimento ocorreu em 2005, de forma que as meninas permaneceram durante um mês institucionalizadas. O segundo acolhimento, da menina mais nova, ocorreu em 2010 e teve duração de seis meses (informação fornecida pela mãe. Segundo equipe técnica, quatro filhos foram acolhidos - 17, 14, 12 e 9 anos). O motivo dos acolhimentos foi a violência física cometida pelo ex-marido de B. (ex-padrasto das adolescentes).

Família C: Está vinculada à instituição de acolhimento 1. A mãe (C.) tem 31 anos e é empregada doméstica, o pai é ausente. C. possui três filhos com idades de 12, 5 e 3 anos e todos residem com ela. Os três passaram pelo acolhimento institucional no ano de 2011 e permaneceram institucionalizados durante três meses. O motivo do acolhimento foi a violência física cometida pelo ex-marido (pai da filha mais nova - falecido há aproximadamente dois anos).

Família D: Está vinculada à instituição de acolhimento 2. A mãe (D.) tem 41 anos e é dona de casa, o pai, de 40 anos, é pedreiro. Os pais são separados e possuem quatro filhos, sendo que apenas um, de 15 anos, reside com a mãe. Além desse adolescente, outro filho (20 anos) também passou pelo acolhimento institucional. $\mathrm{O}$ adolescente de 15 anos permaneceu institucionalizado durante três anos, sendo reintegrado no ano de 2012. O filho mais velho permaneceu institucionalizado durante três dias, sendo em seguida encaminhado ao CASE (Centro de Atendimento Sócio-Educativo). O motivo do acolhimento dos adolescentes foi a evasão escolar do menino mais novo e roubo e violência contra a mãe e uma das irmãs por parte do mais velho.

\section{Procedimentos}

Inicialmente, foi feito contato com as instituições de acolhimento 1 e 2, a fim de apresentar e explicar os objetivos do trabalho à coordenação e à equipe das instituições, as quais aceitaram participar da pesquisa. Após esse contato, o projeto foi submetido ao Comitê de Ética em Pesquisa (CEP) da instituição de ensino superior a qual as pesquisadoras estão vinculadas, sendo aprovado no dia 12/6/2012, sob o parecer n. 36522 e o Certificado de Apresentação para Apreciação Ética n. 03929712.9.0000.5346. Após a aprovação pelo comitê, foi retomado o contato com as instituições a fim de identificar as famílias que seriam convidadas a participar da pesquisa. A escolha dos participantes, bem como o convite para integrar o estudo, deu-se por intermédio das equipes técnicas (psicólogas e assistentes sociais) das instituições.

Foi realizada uma entrevista com cada contexto familiar. As entrevistas tiveram duração média de 35 minutos. Inicialmente a pesquisa previa a realização da entrevista nas instituições. No entanto, considerando-se as especificidades de cada contexto familiar, duas delas ocorreram nas dependências das instituições de acolhimento, e as outras duas, nas residências das famílias. Tal fato deveuse a que, em duas das situações, as mães não tinham possibilidade de comparecer às instituições, solicitando que a entrevista fosse realizada no domicílio.

Duas famílias traziam casos de acolhimento institucional e reinserção familiar de crianças (famílias B e C), e as outras duas, casos de adolescentes (famílias A e D). As entrevistas com as famílias A e B contaram com a participação, além das mães, dos filhos que passaram pela vivência do acolhimento institucional e da reintegração familiar. Tal participação dos adolescentes se deu em função dos mesmos estarem presentes na residência no momento da entrevista e aceitarem participar da mesma. As mães que realizaram a entrevista nas instituições de acolhimento (C. e D.) aproveitaram o horário em que os filhos estavam na escola, por isso eles não participaram. Dessa forma, da família A participou o adolescente L., de 15 anos, e da família B participaram as adolescentes $M$. e N., de 12 e 14 anos respectivamente.

Cenário do estudo

O estudo foi realizado durante o segundo semestre do ano de 2012 em um município de porte médio (de aproximadamente 260.000 
habitantes) do interior do estado do Rio Grande do Sul. Foram contatadas duas instituições de acolhimento para participarem deste estudo, as quais foram denominadas instituição de acolhimento 1 e instituição de acolhimento 2. A instituição 1 é não governamental e atende crianças e adolescentes que precisam de proteção especial. Essa instituição existe desde 1961, porém, em 1986 ela se fundiu com outra que atende meninas adolescentes e permanece assim até os dias atuais. São acolhidas crianças do sexo feminino de $0 \mathrm{a}$ 12 anos e meninos de 0 a 6 anos, a maioria encaminhada pelo Conselho Tutelar. Por meio dos projetos sociais desenvolvidos na instituição, crianças e/ou adolescentes que estejam em situação de vulnerabilidade, mesmo que não estejam acolhidos, podem participar de oficinas no turno inverso ao da escola (projeto Apoio Sócio-Educativo em Meio Aberto - ASEMA). A instituição 2 é governamental, atende adolescentes do sexo masculino e foi fundada em 1999.

\section{Resultados e discussão}

"Eu sempre tive atendimento aqui": articulação da rede de atendimento

Pesquisa realizada por Rizzini et al. (2006) com equipes das instituições de acolhimento apontou que a maioria desses profissionais referiu ser de extrema importância a atuação integrada nesse contexto. Os relatos das mães entrevistadas evidenciam que essas famílias foram acompanhadas pela equipe da instituição de acolhimento durante todo o período em que seus filhos estiveram no acolhimento. Esse acompanhamento está em concordância com a lei n. 12.010 (Brasil, 2009), a qual traz, entre outras orientações, a reavaliação da situação de crianças/adolescentes acolhidos a cada seis meses, a partir de relatórios feitos pela equipe técnica da instituição de acolhimento (Art. 19, § 19). Para que essa avaliação seja feita de forma satisfatória é essencial que a família que tenha filhos acolhidos seja acompanhada desde o momento em que estes ingressem na instituição, aspecto que foi apontado anteriormente como fundamental para o processo de reintegração familiar. Esse acompanhamento parece ficar claro nas seguintes falas:
"Ah, foi a E. e a G. Ipsicóloga 1 e assistente social, respectivamente] que sempre que acompanhou no caso da M. e da N.... foi a E. e a G.[...] eu sempre ia lá conversar com a E.... a E. marcava... ela é psicóloga, então eu ia conversar lá sempre[...]a V. também era atendida pelo psicólogo, a M. também, ela atendia a M. sempre" (B., 41 anos).

"Eu vinha toda terça aqui pra atendimento aqui. Psicóloga[...] com a assistente social, com a G.[...]que ficaram abrigado, eu sempre tive atendimento aqui" (C., 31 anos).

"Sempre [teve atendimento com a equipe da instituição de acolhimento durante a aplicação da medida], até ela [psicóloga 2] cansou de me ajudar até em comida e coisa, né... alimentação e coisa ali, porque eu não tenho nada em casa, né..." (D., 41 anos).

Esse acompanhamento com as famílias realizado pela equipe da instituição de acolhimento parece não ter se restringido apenas ao período de duração da medida de proteção. As falas das mães apontam que os atendimentos continuaram mesmo após a reintegração de seus filhos, tanto através de horários previamente agendados em que as mães deveriam comparecer à instituição de acolhimento, como através de visitas domiciliares realizadas pelos profissionais. Tais depoimentos indicam que teria ocorrido um processo de trabalho envolvendo a família, em especial as mães, tal como a legislação tem preconizado.

"[...]e mesmo assim, depois que eles foram pra casa eu também tinha atendimento até um tempo aqui, que eu tinha atendimento" (C., 31 anos).

"Mas elas lequipe da instituição de acolhimento] foram lá em casa [...] ]e me ligam seguido... seguido elas me ligam e tudo[...] sim [continuaram os atendimentos com a equipe da instituição de acolhimento], só que daí eu fui pro hospital, aí fiquei um mês e pouco, né, aí depois que eu saí... só agora que eu saí [...] mas era pra 'mim vir' toda a sexta com ela [psicóloga 2], né" (D., 41 anos).

As falas das mães parecem indicar que a equipe da instituição de acolhimento seguiu um plano de desligamento e reintegração das crianças e adolescentes sob sua responsabilidade. Esse 
plano, segundo Siqueira (2009), deve incluir, entre outras ações, entrevistas regulares com os meninos e meninas acolhidos e também com seus familiares, visitas domiciliares de um profissional da instituição de acolhimento à família, além de visitas dos familiares às crianças e adolescentes, e vice-versa, antes da reinserção. Essas ações visam avaliar se houve mudança da situação familiar durante o acolhimento, buscando eliminar os riscos aos quais essas crianças e adolescentes estavam expostos antes da aplicação da medida de proteção. Para que a reintegração seja bemsucedida, é essencial que seja desenvolvido um acompanhamento efetivo e integrado das famílias.

Com relação a esse aspecto, as mães identificaram diferenças na forma de atuação dos profissionais quando a experiência do acolhimento foi anterior à lei n. 12.010 (Brasil, 2009). Essas diferenças evidenciaram que, anteriormente à lei, a atuação das equipes não tinha uma participação muito presente, o que pode ser observado no caso de B., que passou pelo primeiro acolhimento de suas filhas em 2005 (antes da lei), e pelo segundo em 2010: "Não, na primeira vez não [havia atendimento]... nunca fui chamada por ninguém. Só mesmo ia visitar [...] e a N., ela nunca teve [...] atendimento com a $E$. [psicóloga 1] só mesmo era eu e a M. que ela falava" (B., 41 anos). Também a adolescente parece ter percebido essa diferença, o que pode ser notado na afirmação "quando eu fui pequena não [eram realizados atendimentos na instituição de acolhimento], só quando eu fui pra lá da segunda vez [no ano de 2010], aí tinha" (M., sexo feminino, 12 anos). Esse aspecto é importante, pois sinaliza que a nova lei estaria produzindo mudanças no cenário do acolhimento e que estas estariam sendo reconhecidas pelos familiares que vivenciam o fenômeno.

Os relatos parecem indicar, também, que houve o envolvimento de outros serviços da rede de atenção nos casos, e que estes pareceram estar articulados, ou seja, havia comunicação entre os serviços acionados. Isso nos permite pensar que teria havido um fluxo de atendimento, o que teria possibilitado um olhar integrado às crianças e adolescentes envolvidos e suas famílias, evitando uma multiplicidade de atendimentos (Rizzini et al., 2006).
"Daí uma professora teve aqui em casa me fazendo uma visita [...] aí veio as professoras e uma vice-diretora tiveram aqui e aí viram que a única coisa que não tinha aqui era bicicleta. Aí a professora do [filho mais novo] arrumou as quatro bicicletas novinhas [...] vem conselheira aqui de vez em quando pra conversar comigo, com ele, com o [marido] [...] daí conversa um pouquinho com a gente aqui e daí já... já vão" (A., 38 anos).

"A M. queria vir pra cá comigo, né, a M. queria morar comigo, mas a gente morava naquela casinha lá que tava caindo aos pedaços, aí não tinha como, né? [...] aí foi quando elas [equipe da instituição de acolhimento 1] conseguiram o... as madeiras pra fazer, que deu esse quarto e mais um pedaço aqui da casa" (B., 41 anos).

"Eu levava a Z. lá no CRAS [CREAS], lá onde... lá no centro. No psicólogo" (C., 31 anos).

"No CAPS ele [X.] teve duas 'vez' também, mas daí a... a doutora liberou ele, disse que ele não tinha nada" (D., 41 anos).

Através dos relatos pôde-se perceber que diversos serviços foram acionados: CAPS, CREAS, Conselho Tutelar, Secretaria de Habitação (no caso da conquista do material para a construção do quarto da adolescente) e também a escola de um dos adolescentes. Isso parece indicar que a rede de atendimento vem sendo acionada, o que pode levar a uma redução do tempo de institucionalização e a uma reinserção bem-sucedida para esses meninos e meninas, na medida em que os problemas estariam sendo tratados.

"Eu acho maravilhoso o que eles fizeram por mim": percepção sobre os serviços prestados pela rede

As mães entrevistadas parecem ter passado por uma experiência bastante positiva com as equipes técnicas das instituições de acolhimento. Ainda que, em alguns casos, as famílias possam não ter compreendido o acolhimento dos filhos como necessário, o trabalho desenvolvido pelos profissionais envolvidos parece ter sido considerado bastante efetivo.

"Aí, eu acho... assim, principalmente desses que me ajudaram agora, eu acho maravilhoso o que eles fizeram por mim... e pelo L. também, senão o pobrezinho 
estaria até hoje lá, né?, então eu acho maravilhoso, né [...] a gente não sabe nem como agradecer" (A., 38 anos).

"Sim, 'foi' bom os atendimentos [da equipe da instituição de acolhimento 1] [...] elas [psicóloga 1 e assistente social] conversavam comigo e tudo... como é que tinha que ser, como é que não tinha que ser [...] pra ajudar eles a 'voltar' [...] ajudou bastante... ajudou" (C., 31 anos).

"Pra mim foi bem bom [atendimentos da equipe da instituição de acolhimento 2] [...] foi bom, ela [psicóloga 2] me ajudou bastante, só a mãe e o pai que me ajudam, daí ela [psicóloga 2] me ajuda bastante, tanto em condições financeiras como psicológicas..." (D., 41 anos).

Parece que o vínculo construído entre as mães e a equipe da instituição de acolhimento foi muito bom nos casos entrevistados, resultando em um trabalho que conseguiu aproximar essas mães da instituição. Construir esse vínculo é fundamental para que sejam criadas e fortalecidas práticas em torno da lei n. 12.010 (Brasil, 2009). Se esse laço entre família e instituição for forte, ele pode facilitar o processo de reintegração familiar, pois a instituição conseguirá trabalhar com a história da criança e de sua família, configurando-se como um "caminho de volta ao lar" (Silva, 2012, p. 62). Nas famílias entrevistadas esse laço parece ter ficado tão forte que a equipe da instituição não foi apenas bem avaliada pelas mães, mas também parece ter ocupado um lugar de referência para elas, como pode ser visto nas seguintes falas:

"A E. [psicóloga 1] é muito importante, até hoje, assim, se a gente tivesse que ir lá e conversar com ela, eu acho muito importante [...] esses tempos até andou acontecendo umas coisas com a M., que eu nem vou falar, que eu disse assim pra ela, que eu ia falar com a E., pra ela ir lá conversar com a E., né, que ela andou aprontando umas coisinhas [...]" (B., 41 anos).

“Claro, me ajudou na minha vida [psicóloga 2], não foi só com o abrigo do X. [...] a $F$. [psicóloga 2] cansou de me ajudar, várias vezes... várias vezes eu tava caída, tava no buraco ali, ó, eu chegava aqui, eu chegava tremendo, eu chegava com... chorando aqui, ó, ela me apoiava e me dava um... uma força e tudo ali" (D., 41 anos).
Também os adolescentes parecem compartilhar dessa mesma percepção com relação aos atendimentos recebidos pela equipe técnica da instituição de acolhimento. Uma das adolescentes referiu achar "legal" os atendimentos com a psicóloga (psicóloga 1) e achar "bom" o atendimento da equipe da instituição de acolhimento (M., 12 anos, sexo feminino). A mãe de $X$. , por sua vez, afirma que para o filho os atendimentos também foram bons, e que a equipe ficou como uma referência para o adolescente, como pode-se perceber através da fala:

"Ele [X.] adora as gurias [da equipe da instituição de acolhimento 2], né... tu precisa ver aquela parede do quarto dele, de foto que tem [...] é da F. [psicóloga 2], é daquela outra aqui, é da [psicóloga] lá do abrigo... bom, a parede é toda, inteira cheia de foto. O meu celular eu tenho que esconder dele, senão ele passa só mandando mensagem e coisa" (D., 41 anos).

A entrada em uma instituição de acolhimento é um momento que gera uma quebra dos laços e lugares conhecidos que pode deixar marcas dolorosas. Dessa forma, a presença de um profissional capacitado pode garantir para a criança ou o adolescente que ele não será abandonado novamente (Guará, 2006). O vínculo criado entre as crianças/adolescentes e a equipe da instituição de acolhimento parece mostrar o esforço da equipe para configurar o acolhimento como um espaço que oferece proteção e segurança para os acolhidos, além de uma atenção individualizada, tal como preconiza a nova lei (Brasil, 2009).

Também as equipes dos serviços da rede acionados para os diferentes casos foram positivamente referidas pelas famílias. As mães parecem ter entendido os encaminhamentos feitos pelas equipes técnicas das instituições de acolhimento como serviços que vieram para somar no processo de reintegração familiar de seus filhos.

"Achei bom [atendimento da filha no CREAS], ela melhorou bastante em casa e tudo [...] era mais agitada, agora não. Não tá agitada mais" (C., 31 anos).

"Ah, pra mim foi bem bom los atendimentos da rede de atendimento] [...] No CAPS também eu tenho psicóloga, eu tenho... 
clínico geral, eu tenho psiquiatra, eu tenho tudo toda a semana, sabe, é bem bom. Pra mim foi bem bom" (D., 41 anos).

A partir das falas dos participantes deste estudo, parece ser possível perceber que as famílias entendem as ações das equipes técnicas das instituições de acolhimento e os atendimentos da rede como trabalhos realizados com vistas à reintegração familiar de seus filhos. Essa percepção parece complementar os resultados do estudo de Silva (2012) que, ao entrevistar profissionais que atuam em instituições de acolhimento, evidencia que estes apontaram trabalhar buscando a reintegração familiar. Esse trabalho desenvolvido pelas equipes técnicas parece estar sendo compreendido pelos familiares envolvidos no fenômeno do acolhimento institucional e reintegração familiar, havendo, dessa forma, um encontro entre os diferentes discursos que compõem o cenário do acolhimento (técnicos, mães e adolescentes).

\section{Considerações finais}

A partir dos relatos das famílias entrevistadas pôde-se perceber que elas identificaram um esforço das equipes técnicas das instituições de acolhimento para prestar um bom atendimento às crianças e adolescentes acolhidos. As mães destacaram que receberam atendimento da equipe durante toda a aplicação da medida de proteção e também após a reinserção de seus filhos. Esse fato está de acordo com os preceitos da lei n. 12.010 (Brasil, 2009), a qual coloca a equipe de atendimento da instituição de acolhimento em uma posição muito mais ativa quanto à institucionalização e reintegração dos meninos e meninas que se encontram acolhidos.

Essa atuação mais ativa da equipe técnica da instituição de acolhimento, como dita anteriormente, parece ter sido notada pelas famílias entrevistadas. As mães e os adolescentes que passaram pelo acolhimento institucional antes e depois do advento da nova lei relataram terem percebido mudanças, principalmente na frequência dos atendimentos oferecidos pela instituição de acolhimento, passando de "praticamente inexistentes", antes da nova lei, para "recorrentes", por vezes mais de uma vez por semana, depois da lei. Essa intensificação dos atendimentos e do acompanhamento dos casos se deve, entre outros fatores, à obrigatoriedade de elaboração de um plano individual de acolhimento para cada criança e adolescente institucionalizado e da reavaliação dos casos a cada seis meses, preceito trazido pela nova lei. Também foi possível perceber, através dos depoimentos, que a rede de atendimento foi acionada no acompanhamento dos meninos e meninas envolvidos no estudo, buscando o serviço especializado mais indicado para cada caso.

Por fim, parece ser importante destacar que mesmo considerando que o fator de desejabilidade do pesquisador possa ter influenciado nos resultados do estudo, certamente pode-se afirmar que mudanças fazem parte da realidade presente no acolhimento institucional, sobretudo nas relações entre família e instituição, na agilidade dos processos e na reintegração familiar. Assim, sugere-se a realização de outros estudos sobre a temática, considerando que a realidade brasileira, por sua amplitude e pluralidade, certamente apresenta especificidades na vivência do acolhimento institucional e da reintegração familiar, sendo este estudo um recorte de um desses contextos. Sugere-se ainda a realização de estudos que tenham como participantes não só as mães, mas outros membros da família, a fim de que se possa ampliar o conhecimento da realidade das famílias brasileiras, e, em especial, daquelas que se encontram atravessadas pelas medidas protetivas. 


\section{Patricia Jovasque Rocha}

Mestranda em Psicologia pela Universidade Federal de Santa Maria, Santa Maria - RS.

Brasil. E-mail: patinhajovasque@hotmail.com

\section{Dorian Mônica Arpini}

Doutora em Psicologia Social pela Pontifícia Universidade Católica de São Paulo, São Paulo - SP. Docente da Universidade Federal de Santa Maria, Santa Maria - RS. Brasil. E-mail: monica.arpini@gmail.com

\section{Sabrina Dal Ongaro Savegnago}

Mestre em Psicologia pela Universidade Federal de Santa Maria, Santa Maria - RS. Brasil.

E-mail: binasavegnago@yahoo.com.br

\section{Endereço para envio de correspondência:}

Universidade Federal de Santa Maria, Centro de Ciências Sociais e Humanas,

Departamento de Psicologia. Floriano Peixoto. Centro. CEP 97010-000 - Santa Maria, RS Brasil.

Recebido 26/11/2013, Aprovado 29/09/2014. 
Referências

Albuquerque, A. B. (2012). Violências em família. In M. I. C. Moreira \& S. D. M. S. Carellos (Eds.), Famílias em vulnerabilidade social: é possível auxiliar sem invavir? (pp. 75-96). Curitiba: Editora CRV.

Arpini, D. M., \& Quintana, A. M. (2009). Família e instituições de abrigo: reconstruindo relações. In D. M. Arpini (Ed.), Psicologia, família e instituição (pp. 9-28). Santa Maria: Editora UFSM.

Bardin, L. (1977). Análise de conteúdo. Lisboa: Editora 70.

Brasil. (1990). Lei n. 8.069, de 13 de julho de 1990. Dispõe sobre o Estatuto da Criança e do Adolescente e dá outras providências. Diário Oficial da União, Brasília, DF, Seção 1.

Brasil. (2009). Lei n. 12.010, de 3 de agosto de 2009. Dispõe sobre adoção; altera as Leis nos 8.069, de 13 de julho de 1990 - Estatuto da Criança e do Adolescente, 8.560, de 29 de dezembro de 1992; revoga dispositivos da Lei no 10.406, de 10 de janeiro de 2002 Código Civil, e da Consolidação das Leis do Trabalho - CLT, aprovada pelo Decreto-Lei no 5.452, de 1o de maio de 1943; e dá outras providências. Diário Oficial da União, Brasília, DF, Seção 1.

Cavalcante, L. I. C., Silva, S. S. C., \& Magalhães, C. M. C. (2010). Institucionalização e reinserção familiar de crianças e adolescentes. Revista Mal-Estar e Subjetividade, 10(4), 1147-1172. Recuperado em 10 de março de 2013, da PePSIC (Periódicos Eletrônicos em Psicologia): http://pepsic.bvsalud.org/scielo.php?pid=S1518$61482010000400005 \&$ script $=$ sci_arttext

Gaskell, G. (2005). Entrevistas individuais e grupais. In M. W. Bauer \& G. Gaskell (Eds.), Pesquisa qualitativa com texto, imagem e som: um manual prático (pp. 64-89). Petrópolis: Editora Vozes.

Guará, I. M. F. R. (2006). Abrigo: comunidade de acolhida e socioeducação. In M. V. Baptista (Ed.), Abrigo: comunidade de acolhida e socioeducação (pp. 63-75). São Paulo: Instituto Camargo Corrêa.

Lopes, M. D. C., \& Arpini, D. M. (2009). Retratos da infância: um olhar voltado às instituições de abrigo. In D. M. Arpini (Ed.), Psicologia, família e instituição (pp. 89-128). Santa Maria: Editora UFSM.

Moreira, J. S. S., \& Miranda, V. R. (2014). Reinserção familiar: sim ou não? Diferentes facetas de uma longa e difícil história familiar. In M. C. N. Carvalho \& V. R. Miranda (Eds.), Psicologia Jurídica: temas de aplicação (pp. 61-78). Curitiba: Juruá.

Oliveira, R. C. S. (2007). Quero voltar para casa. São Paulo: Aasptj.

Richardson, R. J. (1999). Pesquisa social: métodos e técnicas. São Paulo: Atlas.

Rizzini, I., Rizzini, I., Naiff, L., \& Baptista, R. (2006). Acolhendo crianças e adolescentes: experiências de promoção à convivência familiar e comunitária no Brasil. São Paulo: Cortez.

Rossetti-Ferreira, M. C., Almeida, I. G., Costa, N. R. A., Guimarães, L. A., Mariano, F. N., Teixeira, S. C. P. et al (2012). Acolhimento de crianças e adolescentes em situações de abandono, violência e rupturas. Psicologia: Reflexão e Crítica, 25(2), 390-399. http://dx.doi. org/10.1590/S0102-79722012000200021.

Serrano, S. A., Almeida, I. G., \& Rossetti-Ferreira, M. C. (2013). A criança no acolhimento institucional. In L. V. C. Moreira (Ed.), Psicologia, família e direito: interfaces e conexões (pp. 161-176). Curitiba: Juruá.

Silva, E. R. A., Mello, S. G., \& Aquino, L. M. C. (2004). Os abrigos para crianças e adolescentes e a promoção do direito à convivência familiar e comunitária. In E. R. A. Silva (Org.), O direito à convivência familiar e comunitária: os abrigos para crianças e adolescentes no Brasil (pp. 209-242). Brasília: IPEA; CONANDA.

Silva, M. L. (2012). Lei Nacional de adoção e acolhimento institucional: o ponto de vista de psicólogos e assistentes sociais. Dissertação de Mestrado, Programa de Pós Graduação em Psicologia, Universidade Federal de Santa Maria, Santa Maria.

Silva, M. L., \& Arpini, D. M. (2013). A nova lei nacional de adoção - desafios para a reinserção familiar. Psicologia em Estudo, 18(1), 125-135. http://dx.doi.org/10.1590/ S1413-73722013000100013.

Siqueira, A. C. (2009). Reintegração familiar: discutindo a interface do risco e da proteção nos casos de reinserção familiar de crianças e adolescentes institucionalizados. In D. M. Arpini (Ed.), Psicologia, família e instituição (pp. 55-88). Santa Maria: Editora UFSM. 
Patricia Jovasque Rocha, Dorian Mônica Arpini \& Sabrina Dal Ongaro Savegnago

Siqueira, A. C. (2012). A garantia ao direito à convivência familiar e comunitária em foco. Estudos de Psicologia, 29(3), 437-444. http:// dx.doi.org/10.1590/S0103-166X2012000300013.

Siqueira, A. C., \& Dell'Aglio, D. D. (2012). Crianças e adolescentes institucionalizados: desempenho escolar, satisfação de vida e rede de apoio social. Psicologia: Teoria e Pesquisa (Brasília), 26(3), 407-415.

Souza, M., \& Carvalho, M. C. N. (2014). Psicologia jurídica nos abrigos: uma análise sistêmica do direito à convivência familiar e comunitária. In M. C. N. Carvalho \& V. R. Miranda (Eds.), Psicologia Jurídica: temas de aplicação (pp. 21-42). Curitiba: Juruá.

Turato, E. R. (2003). Tratado de metodologia da pesquisa clínico-qualitativa. Petrópolis: Editora Vozes.

Vitale, M. A. F. (2006). Famílias: pontos de reflexão. In M. V. Baptista (Ed.), Abrigo: comunidade de acolhida e socioeducação (pp. 77-85). São Paulo, Brasil: Instituto Camargo Corrêa. 